\title{
Avaliação das condições de higiene dos carrinhos ambulantes de água de coco comercializada em Brasília (DF)
}

\author{
Laura Parente Ribeiro ${ }^{1}$ \\ Antônio Felipe Correa Marangon²
}

\section{Resumo}

O consumo da água de coco verde comercializada em carrinhos ambulantes no país é crescente e significativo, colocando em risco a saúde do consumidor. O presente estudo objetivou avaliar as condições de higiene da comercialização de água de coco em carrinhos ambulantes na cidade de Brasília, Distrito Federal. Os principais aspectos analisados foram as condições de higiene dos manipuladores, condições das instalações dos carrinhos ambulantes, de conservação e higienização dos utensílios utilizados para a comercialização da água de coco. Com base na RDC no ${ }^{\circ} 216$ - BPF, a pesquisa revelou a falta de condições para a higienização de utensílios, a deficiência quanto à manipulação, a falta de informação básica de educação sanitária dos comerciantes, a conservação e o armazenamento inadequados dos produtos. Concluiu-se que o comércio ambulante de água de coco em Brasília não possui as condições básicas para o correto controle higiênico-sanitário.

Palavras-chave: Água de coco. Condições higiênico-sanitárias. Carrinhos ambulantes. Boas práticas.

\section{Introdução}

O consumo de alimentos comercializados nas ruas é um hábito cultural disseminado pelo mundo todo (GERMANO, M.; GERMANO, P., 2000). A venda desses alimentos na rua pode constituir um risco à saúde dos consumidores, uma vez que os alimentos podem ser facilmente contaminados por microrganismos

\footnotetext{
1 Formanda em nutrição no Centro Universitário de Brasília.

2 Professor do Curso de Nutrição do Centro Universitário de Brasília, email: felipe. marangon@uniceub.br.
} 
patogênicos, principalmente devido às condições inadequadas do local de preparo, à falta de conhecimento de técnicas de manipulação higiênica, à falta de infraestrutura dificultando a higienização dos utensílios utilizados e ainda à higiene pessoal (RODRIGUES et al, 2003; CARDOSO et al., 2003).

O consumo da água de coco verde comercializada em carrinhos ambulantes no país é crescente e significativo. Esse crescimento tem estimulado a busca pela modernização e profissionalização nos processos de distribuição e comercialização, para garantir ainda mais o crescimento do mercado (HOFFMAN et al., 2002; MAGALHÃES et al., 2005).

A água de coco é um produto estéril, quando no interior do fruto; entretanto, devido a sua composição rica em nutrientes, torna-se muito suscetível ao crescimento microbiano, fazendo-se necessário um controle microbiológico. Outro fator considerável é a atividade enzimática naturalmente presente no líquido. Apesar de essas enzimas apresentarem finalidades específicas e vitais para o fruto in vivo, em contato com a atmosfera desencadeiam reações indesejáveis como, por exemplo, o desenvolvimento de uma coloração rosada. (FORTES et al., 2006; ANDRADE, 2008).

É importante salientar que a atividade ambulante da venda de água de coco é geralmente exercida por pessoas que devem ser adequadamente treinadas em conceitos de higiene, sanitização e boas práticas de manipulação, tendo como finalidade evitar que os produtos sejam contaminados por agentes físicos, químicos ou biológicos provenientes da pessoa que manipula, do local e dos utensílios. A adoção das Boas Práticas de Fabricação (BPF) representa uma das importantes ferramentas para o alcance de níveis adequados de segurança (BRASIL, 2004).

\section{Metodologia}

Foi realizado um estudo analítico e transversal da higiene dos carrinhos ambulantes que comercializam água de coco nos parques Olhos D’água e Sarah Kubitschek, Brasília/Distrito Federal, em funcionamento no momento da coleta dos dados. 
A coleta dos dados ocorreu durante um sábado e um domingo do mês de abril de 2010, pela manhã, porque são horários de grande movimento nos parques e, provavelmente, haveria a presença de mais ambulantes de água de coco.

Em função da ausência de legislação específica para ambulantes, optou-se pela realização do estudo analítico, utilizando um roteiro de observação pré-confeccionado, baseado na Resolução Federal RDC nº 216 - BPF, de 15 de setembro de 2004. Esse roteiro foi modificado pelo pesquisador deste estudo e elaborado por Beiró e Silva (2009), avaliando as conformidades e não conformidades dos estabelecimentos que comercializam alimentos numa feira livre do Distrito Federal.

Os principais aspectos analisados foram as condições de higiene dos manipuladores e das instalações dos carrinhos ambulantes, além da conservação e higienização dos utensílios utilizados.

Não foi necessário aprovação desta pesquisa pelo comitê de ética da instituição de ensino superior, pois se tratou de um estudo observacional, o pesquisador estando próximo ao "ambulante" e verificando todos os pontos do roteiro de observação.

\section{Resultados}

No momento da coleta de dados, foi observado que nos parques Olhos D'água e Sarah Kubitschek, havia 8 carrinhos ambulantes que comercializavam água de coco.

Os resultados obtidos mostraram que todos os carrinhos avaliados não apresentaram instalações para a devida higienização de utensílios, alimentos e manipuladores. Além disso, observou-se que, 50\%, ou seja, 4 carrinhos possuíam equipamento de conservação da água de coco, como refrigeradores $(n=2)$ e isopores $(n=2)$. 
Os utensílios não foram higienizados em 100,0\% (n=8) dos carrinhos que comercializavam água de coco, sendo que esses utensílios apresentavam um estado de conservação bom (50\%) ou regular (50\%), como pode ser observado na Tabela 1.

Tabela 1 - Estado de Conservação do Utensílio.

\begin{tabular}{cccc}
\hline \hline \multirow{2}{*}{ Estado de Conservação do Utensílio } & \multicolumn{2}{c}{ Frequência } \\
& Absoluta & Relativa \\
\hline \hline Ótimo & 0 & $0,00 \%$ \\
Bom & 4 & $50,00 \%$ \\
Regular & 4 & $50,00 \%$ \\
Péssimo & 0 & $0,00 \%$ \\
\hline \hline Total & 8 & $100 \%$ \\
\hline \hline
\end{tabular}

Não foram observadas feridas nas mãos dos manipuladores dos 8 carrinhos avaliados, e, apenas $3(37,5 \%)$ ambulantes implantaram a utilização de uniformes, sendo que, dentro dessa amostra, a cor mais comum foi o branco com $66,67 \%$ $(n=2)$, seguida do verde-claro com 33,33\% $(n=1)$. Porém, esses uniformes não estavam completos, tendo em vista que $62,5 \%(n=5)$ de todos os carrinhos não utilizavam nenhuma proteção que envolvesse os cabelos, dado que pode ser observado mediante a Tabela 2 .

Tabela 2 - Utilização de proteção para os cabelos

\begin{tabular}{cccc}
\hline \multirow{2}{*}{ Utilização de Toucas ou Boné } & \multicolumn{2}{c}{ Frequência } \\
& Absoluta & Relativa \\
\hline \hline Não & 5 & $62,50 \%$ \\
Sim & 3 & $37,50 \%$ \\
\hline \hline Total & 8 & $100,00 \%$ \\
\hline \hline
\end{tabular}

Durante a observação, também foi avaliado o comportamento dos trabalhadores em relação à manipulação de alimentos e dinheiro; e, nesse caso, 87,5\% ( $\mathrm{n}=$ 7) deles manipulavam os dois ao mesmo tempo. E todos os ambulantes (100\% dos manipuladores) não lavavam as mãos após a troca de função.

A utilização de adornos durante a produção é uma prática comum, uma vez que, $62,5 \%(n=5)$ dos trabalhadores observados usavam algum tipo de adorno. 
Em relação ao estado das unhas pode-se analisar os resultados através da Tabela 3. Foi observado que apenas $12,5 \%(n=1)$ dos manipuladores apresentavam as unhas sujas e que $50 \%(n=3)$ apresentavam as unhas cortadas.

Tabela 3 - Estado das unhas dos manipuladores

\begin{tabular}{cccc}
\hline \hline & \multicolumn{2}{c}{ Frequência } \\
Estado das Unhas dos Manipuladores & Absoluta & Relativa \\
\hline Cortadas & 4 & $50,00 \%$ \\
Pintadas & 0 & $0,00 \%$ \\
Limpas & 3 & $37,50 \%$ \\
Sujas & 1 & $12,50 \%$ \\
\hline \hline Total & 8 & $100,00 \%$ \\
\hline \hline
\end{tabular}

Com respeito à utilização de luvas, foi observado que, durante o tempo da coleta de dados, esse item não foi utilizado por nenhum dos observados.

\section{Discussão}

Os comerciantes devem contar com um sistema de abastecimento de água tratada para viabilizar a higienização correta das mãos, utensílios e alimentos, bem como para o preparo e comercialização dos produtos. Os resultados obtidos neste estudo demonstraram que $100 \%$ dos carrinhos avaliados possuíam irregularidades de acordo com a Resolução no 216 do Ministério da Saúde (BRASIL, 2004), que dispõe sobre o Regulamento Técnico de Boas Práticas para Serviços de Alimentação. Sendo assim, esses produtos comercializados estavam em condições higiênicas insatisfatórias, apresentando possibilidade de contaminação. Ressalte-se que, em uma pesquisa realizada por Hoffman et al. (2002) sobre o assunto, constatou-se contaminação por bactérias aeróbias mesófilas em 58,3\% (n=7) das doze amostras de água de coco analisadas, sendo classificados como produtos característicos de condições higiênicas insatisfatórias e impróprio para o consumo, capaz de causar enfermidades transmitidas por alimentos.

Comerciantes que processam o coco verde para obtenção da água enfrentam problemas relativos ao transporte e ao armazenamento, como reações enzimáticas e microbiológicas que modificam as qualidades organolépticas e a potabilida- 
de desse produto (CURSINO et al., 1996). Por esse motivo, é vital que os carrinhos que comercializam esse alimento utilizem equipamentos para a conservação e armazenamento do produto, proporcionem ambientes adequados para retardar as reações químicas e a ação das enzimas, bem como retardar ou inibir o crescimento e atividade dos microrganismos que se encontram nos alimentos (FERREIRA NETO et al., 2004).

Nesta pesquisa, apenas $50 \%(n=4)$ dos carrinhos ambulantes observados possuíam equipamentos (refrigeradores, isopores) para a conservação, ou armazenamento dos frutos, sendo que os restantes armazenavam os cocos no chão ou em sacos plásticos. Embora sejam encontrados trabalhos sobre a conservação da água de coco de maneira comercial, a literatura a respeito da conservação do coco (fruto) é escassa, por isso evidencia-se a importância de estudos para serem encontrados procedimentos adequados de lavagem, desinfecção, armazenamento e conservação dos frutos para posterior extração da sua água, seguidos de tratamentos para inibição ou mesmo inativação do seu sistema enzimático.

Em relação à higiene dos utensílios utilizados para a abertura do coco, $100 \%$ $(n=8)$ dos manipuladores não o fizeram durante a coleta de dados. Esse fato pode acontecer pela falta de abastecimento de água tratada, e/ou pela falta de treinamento e conscientização dos manipuladores, fatores esses que dificultam a prática de medidas de higiene que protejam os alimentos de contaminações microbiológicas. As falhas nos procedimentos de higienização dos utensílios permitem que os resíduos se fixem na superfície deles e se transformem em uma potencial fonte de contaminação cruzada (CHESCA, 2003).

O utensílio encontrado para a perfuração do coco em todos os carrinhos ambulantes foi a broca de aço, estando $50 \%(n=4)$ em bom estado de conservação e $50 \%$ em regular estado de conservação. Os critérios utilizados pelo pesquisador para a caracterização da conservação dos utensílios foram avaliados da seguinte forma: "ótimo", para o utensílio bem conservado, livre de pontos escuros, sujidades, furos e amassamentos; "bom" para os utensílios que estavam bem conservados, livres de pontos escuros, furos e amassamentos, apenas apresentando sujidades da própria matéria-prima; "regular" para utensílios que apresentavam sujidades da 
própria matéria-prima, poucos amassamentos e pontos escuros; e "péssimo" para os utensílios que apresentaram conservações inadequadas, com sujidades, pontos escuros, furos e amassamentos.

Segundo Beiró e Silva (2009), ferimentos nas mãos dos manipuladores são grandes fontes de contaminação para o alimento, pois um dos princípios básicos de higiene é não manipular alimentos se estiver doente ou apresentar algum tipo de lesão nas mãos e unhas. Entretanto, neste estudo, não foram encontradas injúrias nas mãos dos manipuladores que comercializam água de coco.

Um uniforme básico para manipuladores de alimentos deve conter calça comprida e camisa em bom estado de conservação, sapatos fechados e touca de proteção nos cabelos (BRASIL, 2004). O estudo de Valverde e Badaró (2009) teve como conclusão um resultado alarmante, pois nenhum dos manipuladores entrevistados utilizava o uniforme completo.

Também no presente estudo, a utilização de uniformes básicos não foi unânime como deveria ser. Observou-se que, 37\% dos estabelecimentos implantaram parcialmente a utilização de uniformes. Dentre os itens que faltavam, foi constatado também que $62,5 \%(n=5)$ de todos os manipuladores não utilizavam nenhuma proteção que envolvesse os cabelos.

A pesquisa desenvolvida por Sousa et al. (2007) demonstrou que 17\% dos manipuladores são fumantes, falam e manuseiam dinheiro ao manipular o alimento. A pesquisa atual constatou que $87,5 \%(n=7)$ dos trabalhadores manipulavam dinheiro e alimentos ao mesmo tempo, sem a higienização das mãos após a troca de funções, como dispõe a Resolução nº 216 do Ministério da Saúde (BRASIL, 2004). Uma das explicações para esse alto índice seria que nenhum carrinho que comercializa o produto apresentava instalação disponível para a devida higienização das mãos. Segundo Cardoso et al. (2003), o hábito de lavar as mãos é crucial, tendo em vista que as mãos são veículos de microrganismos para o alimento comercializado.

Mallon e Bortolozo (2004) concluíram em seus estudos que 76,4\% dos manipuladores ambulantes que comercializavam alimentos na região central da cidade de 
Ponta Grossa, Estado do Paraná, não apresentavam asseio pessoal favorável (utilizavam adornos, esmalte, tinham unhas compridas e falta de boa apresentação corporal).

Em relação à utilização de adornos nesta pesquisa, foi possível observar que em $62,5 \%(n=5)$ dos locais, os trabalhadores usavam algum tipo de adereço corporal, como brincos, anéis, pulseiras e colares. O presente estudo também avaliou as condições das unhas, constatando que $12,5 \%(n=1)$ dos manipuladores apresentaram unhas sujas e nenhum apresentou unhas pintadas. É de grande importância manter as unhas curtas, sem esmalte ou base e não usar adornos, pois, segundo Lucca e Torres (2002), os manipuladores constituem uma das mais importantes fontes de contaminação dos alimentos, e a manipulação inadequada pode não somente veicular microrganismos patogênicos como também propiciar o desenvolvimento e a sobrevivência desses patógenos.

No estudo, pôde ser observado que nenhum dos manipuladores de água de coco utilizava luvas, uma vez que o uso de luvas em serviços de alimentação não é obrigatório, segundo a Portaria SVS/MS n 326, de 30 de julho de 1997. Porém, o emprego de luvas pode ocorrer desde que sejam observadas as perfeitas condições de higiene e limpeza delas. No entanto, seu uso não exime o manipulador da obrigação de lavar as mãos cuidadosamente (BRASIL, 2004).

Segundo os resultados obtidos, ficou evidenciado que a comercialização de água de coco em carrinhos ambulantes em dois parques de Brasília (DF), não apresenta condições básicas de correto controle higiênico-sanitário do produto. Fatores como a falta de condições para a higienização de utensílios, a deficiência quanto à manipulação e inadequada conservação e armazenamento dos produtos evidenciam a afirmação inicial.

\section{Conclusão}

O rápido crescimento de pontos de venda ambulantes em Brasília (DF), associados ao aumento do consumo dos produtos ali comercializados, coloca em risco a saúde do consumidor. 
Esses resultados obtidos servem de alerta para as autoridades sanitárias do governo e para a criação de uma legislação específica, visando um maior controle dos estabelecimentos ambulantes que comercializam produtos, como a água de coco, a fim de garantir a qualidade e a saúde do consumidor. Também é imprescindível a educação e o treinamento dos manipuladores desses produtos, de forma que se conscientizem de sua responsabilidade em relação à saúde e à segurança dos consumidores.

Sugerem-se estudos em outros locais (ex.: supermercados) para que se possa mostrar à sociedade e às autoridades a realidade sobre as condições higiênico-sanitárias da comercialização de água de coco em carrinhos ambulantes em Brasília (DF).

\section{Evaluation of hygiene pushcart of coconut water marketed in Brasilia (DF).}

\section{Abstract}

Consumption of green coconut water sold in street carts in the country is significant and growing, putting at risk the health of consumers. This study aimed to evaluate the hygiene conditions of the sale of coconut water carts made by hawkers in the city of Brasilia, Federal District. The main aspects examined were the conditions of hygiene of food handlers, conditions of facilities of the stands and street maintenance and cleaning of utensils used for the commercialization of coconut water. Based on the RDC. 216 - GMP, research revealed such factors as the lack of conditions for the sanitation of utensils, the deficiency on the handling, lack of basic information for health education of traders and inadequate conservation and storage of products. We conclude that the street stands selling coconut water are lacking the basic conditions for proper hygienic control.

Keywords: Coconut water. Conditions of hygienic sanitary. Carts made by hawkers. Good practice. 


\section{Referências}

ANDRADE, M. V. V. et al. Avaliação microbiológica da água de coco. In: SIMPÓSIO MINEIRO DE MICROBIOLOGIA DOS ALIMENTOS, 3., 2008, Viçosa, MG. Anais... Viçosa, MG: UFV, 2008.

BADARÓ, A. C. L. Boas práticas para serviços de alimentação: um estudo em restaurantes comerciais do município de Ipatinga. 2007. 172 f. Dissertação (Mestrado)-Departamento de Nutrição e Saúde, Universidade Federal de Viçosa, Viçosa, MG, 2007.

BEIRÓ, F. F. C.; SILVA, C. M. Análise das condições de higiene na comercialização de alimentos em uma feira livre do Distrito Federal. Universitas: Ciências da Saúde, Brasília, v. 7, n. 1, p. 13-28, jan./jun. 2009. doi: 10.5102/ucs.v7i1.883

BRASIL. Ministério da Saúde. Resolução RDC no 216, de 15 de setembro de 2004. Dispõe sobre o regulamento técnico de boas práticas para serviços de alimentação. Brasília, 2004. Disponível em: <http://bvsms.saude.gov.br/bvs/saudelegis/anvisa/2 004 / res0216_15_09_2004.html>. Acesso em: 20 out. 2010.

CARDOSO, R. C. V. et al. Comida de rua: um espaço para estudo na Universidade Federal da Bahia. Revista Higiene Alimentar, São Paulo, v. 17, n. 111, p. 12-17, ago. 2003.

CHESCA, A. C. et al. Equipamentos e utensílios de unidades de alimentação e nutrição: um risco constante de contaminação das refeições. Revista Higiene Alimentar, São Paulo, v. 17, n. 114/115, p. 20-23, nov./dez. 2003.

CUENCA, M. A. G. et al. Mercado brasileiro do coco: situação atual e perspectivas. In: ARAGÃO, W. M. Coco: pós-colheita. Brasília: Embrapa Informação Tecnológica, 2002. p. 18.

CURSINO, M. M. et al. Contribuição à industrialização da água de coco (Cocus nucifera, $L$.) verde. In: CONGRESSO BRASILEIRO DE CIÊNCIA E TECNOLOGIA DE ALIMENTOS, 15, 1996, Poços de Caldas. Anais...Poços de Caldas: SBCTA, 1996.

FERREIRA NETO, J. et al. Avaliação da eficiência no uso dos equipamentos de refrigeração utilizados na conservação de frutas e hortaliças no entreposto terminal de São Paulo (CEAGESP). 2004. Disponível em: <http://www.feagri. unicamp.br/energia/agre2004>. Acesso em: 5 maio 2010. 
FORTES, E. P. et al. Qualidade físicoquímica e microbiológica das águas de coco envasadas, comercializadas em Teresina, Piauí. Revista Higiene Alimentar, São Paulo, v. 20, n. 141, p. 87-90, 2006.

FRANCO, B. D. G. de M.; LANDGRAF, M. Microrganismos Patogênicos de Importância em Alimentos. In: . Microbiologia dos alimentos. São Paulo: Atheneu, 2002. p. 33-71.

GERMANO, M. I. S; GERMANO, P. M. L. Comida de rua: prós e contras. Revista Higiene Alimentar, São Paulo, v. 14, n. 77, p. 27-33, out. 2000.

HOFFMAN, F. L. et al. Qualidade microbiológica de amostras de água de coco vendidas por ambulantes na cidade de São José do Rio Preto - SP. Revista Higiene Alimentar, São Paulo, v. 16, n. 97, p. 87-92, jun. 2002.

LUCCA, A.; TORRES, E. A. Condições de higiene de "cachorro-quente" comercializado em vias públicas. Revista de Saúde Pública, São Paulo, v. 36, n. 3 , p. 350-352, jun. 2002. doi:10.1590/S0034-89102002000300015.

MALLON, C.; BORTOZOLO E. A. F. Q. Alimentos comercializados por ambulantes: uma questão de segurança alimentar. Publicatio UEPG: Ciências Biológicas e da Saúde, Ponta Grossa, v. 10, n. 3, p. 65-76, set./dez. 2004.

MAGALHAES, M. P. et al. Conservação de água de coco verde por filtração com membrana. Ciência e Tecnologia de Alimentos, Campinas, v.25, n.1, p.72-77, jan./ mar. 2005. doi:10.1590/S0101-20612005000100012.

RODRIGUES, K. L. et al. Condições higiênico-sanitárias no comércio ambulante de alimentos em Pelotas-RS. Ciência e Tecnologia de Alimentos, Campinas, v. 23, n. 3, p. 447-452, set./dez. 2003. doi:10.1590/S0101-20612003000300026.

ROSA, M. F.; ABREU, F. A. P. Água de coco: métodos de conservação. Fortaleza: Embrapa/CNPAT/SEBRAE-CE, 2000. 40 p. (Série Documentos n 37). Disponível em: <http://www.cnpat.embrapa.br/cnpat/cd/jss/acervo/Dc_037.pdf> Acesso em: 06 jun. 2011.

SOUSA, J. M. B. et al. Avaliação do perfil higiênico: sanitário dos estabelecimentos comerciais e manipuladores de carne bovina na feira livre de bananeiras - PB. 2007. Disponível em: <http://www.seminagro.com.br/trabalhos_ publicados/2jornada/02ciencia_e_tecnologia_de_alimentos/40cta.pdf $>$. Acesso em: 20 abr. 2010. 
| Universitas: Ciências da Saúde, Brasília, v. 9, n. 1, p. 1-12, jan./jun. 2011
Laura Parente Ribeiro, Antônio Felipe Correa Marangon

VALVERDE, R. C.; BADARÓ, C. A. Qualidade microbiológica da água de coco comercializada por ambulantes na cidade de Ipatinga, Minas Gerais. Revista

Nutrir Gerais, Ipatinga, v. 3, n. 5, p. 489-504, ago./dez. 2009. 